\title{
BONES IN PSEUDOHYPOPARATHYROIDISM TYPE 1A
}

\author{
S. Savić ${ }^{1}$ M. Stojković1 ${ }^{1}$ B.Beleslin ${ }^{1,2}$, T. Lalić $^{1}$, M. Barać $^{1}$, T. Nišić1, M. Stojanović ${ }^{1,2}$, J. Ćirić $^{1,2}$, \\ M. Žarkovićc ${ }^{1,2}$ \\ ${ }^{1}$ Clinic of endocrinology, diabetes and metabolic disorders, Clinical Centre of Serbia, Belgrade \\ ${ }^{2}$ Belgrade University School of Medicine, Serbia
}

Objectives:

Methods:
Pseudohypoparathyroidism type 1a (PHP1a) is disorder characterised by resistance to the biological actions of circulating parathyroid hormone (PTH) along with typical features of Albright's hereditary osteodystrophy (AHO). Tissue-specific imprinting of GNAS gene results in complete resistance to PTH in renal proximale tubule, but skeletal responsiveness to PTH appears intact, since Gas is biallelically expressed in human bones.

The objective of this study was to determine BMD, and its relation to PTH levels in a group of young adult patients with PHP1a (age range 19-32yr).

BMD measurements (Hologic QDR 4500) at the lumbar spine (LS), total hip (TH) and femoral neck (FN) were obtained in 5 patients with PHP1a (diagnosis was based on presence of AHO features combined with multihormone resistance). All patients were diagnosed with this condition earlier, and treatment was begun between ages 4 and 21 yr.
Caracteristics of study patients: intact PTH levels ranged from 120.9 to $436 \mathrm{pg} / \mathrm{ml}$ (reflecting inadequate dosing of calcium and calcitriol); all patients were taking levothyroxine and TSH levels were mildly elevated (range 5.98-12.10mIU/L); three subjects were $\mathrm{GH}$ deficient, and none recieved $\mathrm{GH}$ therapy.

The mean BMD Z-score for the LS was -1.4 (range -2.6 to -0.6 ), which is not significantly different from normal. Three subjects had Z-scores out of \pm 1 , range expected for the normative population, and one of them met the criteria for low BMD. The mean BMD Zscore for the TH was -1.1 (range -1.6 to -0.8 ), and for the FN was -0.8 (range -1.9 to 0.2 ), both not significantly different from normal controls.

Our results show that subjects with PHP1a, despite significant secondary hyperparathyroidism, had normal bone mass, with exept of one subject $(20 \%)$ who had Iow LS BMD. These results are somewhat conflicting with previous study wich demonstrated that bone mass is either normal or increased in PHP1a.

1. Mantovani G, Bondioni S, Locatelli M, Pedroni C, Lania AG, Ferrante E, Filopanti M, Beck-Peccoz P, Spada A. Biallelic expression of the Gsa gene in human bone and adipose tissue. J Clin Endocrinol Metab. 2004; 89(12):6316-6319.

2. Long DN, Levine MA, Germain-Lee EL. Bone mineral density in pseudohypoparathyroidism type 1a. J Clin Endocrinol Metab. 2010; 95(9):4465-4475.

3. Levine MA. An update on the clinical and molecular characteristics of pseudohypoparathyroidism. Curr Opin Endocrinol Diabetes 2012; 19(6): 443-451. 